\title{
Contribution of Family, Behavioral, and Neuropsychological Factors to Long-Term Functional Outcomes in Young Adults with ADHD: A 12-Year Follow-Up Study
}

\author{
Ana Miranda ${ }^{1}$, Carmen Berenguer ${ }^{1, *}$ (D) Belen Rosello ${ }^{1}$, José Martínez-Raga ${ }^{1,2}$ and Fernando Mulas ${ }^{3}$ \\ 1 Developmental and Educational Psychology, University of Valencia, 46010 Valencia, Spain; \\ ana.miranda@uv.es (A.M.); m.belen.rosello@uv.es (B.R.); Jose.Martinez-Raga@uv.es (J.M.-R.) \\ 2 Unidad de Psiquiatría y Psicología Clínica, Hospital Universitario Dr. Peset, University of Valencia, \\ 46017 Valencia, Spain \\ 3 Instituto Valenciano Neurología Pediátrica (INVANEP), 46010 Valencia, Spain; fernando.mulas@invanep.com \\ * Correspondence: carmen.berenguer@uv.es; Tel.: +34-96-3983840
}

check for updates

Citation: Miranda, A.; Berenguer, C.; Rosello, B.; Martínez-Raga, J.; Mulas,

F. Contribution of Family, Behavioral, and Neuropsychological Factors to Long-Term Functional Outcomes in Young Adults with ADHD: A 12-Year Follow-Up Study. Sustainability 2021, 13, 814. https://doi.org/ $10.3390 /$ su13020814

Received: 16 December 2020 Accepted: 11 January 2021 Published: 15 January 2021

Publisher's Note: MDPI stays neutral with regard to jurisdictional clai$\mathrm{ms}$ in published maps and institutional affiliations.

Copyright: (C) 2021 by the authors. Licensee MDPI, Basel, Switzerland. This article is an open access article distributed under the terms and conditions of the Creative Commons Attribution (CC BY) license (https:// creativecommons.org/licenses/by/ $4.0 /)$.

\begin{abstract}
The persistent nature of attention deficit hyperactivity disorder (ADHD) and the role of behavioral factors in its continuity have been widely documented in the literature. However, less is known about the role of early family and neuropsychological factors in predicting later adaptive functioning and quality of life in individuals with ADHD. This study aimed to analyze the contribution of early family, behavioral, and neuropsychological factors to long-term functional outcomes in young adults with ADHD. Family (parental mood disorders, family risk index, parenting stress, coherence), behavioral (oppositionism, inattention, emotional lability, hyperactivity), and cognitive factors were examined at baseline. Twelve years later, daily life functioning, quality of life, and executive and behavioral functioning were also evaluated in 61 young adults with a childhood diagnosis of ADHD. Results revealed significant correlations between most of the family and behavioral factors at baseline and the long-term functional outcomes. Specifically, multiple regressions showed that mothers' depression and laxness predicted later quality of life, executive functioning, and the hyperactivity index, and mothers' depression and parenting stress at baseline also significantly predicted the hyperactivity index. Oppositionism behavior and inhibition were also significant predictors of the hyperactivity index. Therefore, understanding the family, behavioral, and neuropsychological factors that can contribute to later quality of life, daily functioning, and behavioral and executive functions is a particularly critical issue in detecting and planning efficacious ADHD interventions.
\end{abstract}

Keywords: ADHD; family; behavior; neuropsychological factors; quality of life; daily functioning; executive functions; follow-up study

\section{Introduction}

ADHD is a neurodevelopmental disorder characterized by inappropriate levels of inattention, impulsivity, and hyperactivity. Although the core symptoms tend to improve with age, persistence rates in adulthood reach close to $40-50 \%$ of the cases [1]. Moreover, $65 \%$ of clinically-referred children with ADHD continue to have symptoms as young adults [2], which adversely affects their social, academic, or occupational functioning and places a significant burden on the family and society [3]. The negative outcomes are present in various areas, including poor self-esteem [4] and increased rates of oppositional-defiant disorder [5,6], antisocial personality disorder [7], depression and anxiety [8,9], substance use disorders [10], and executive function (EF) deficits [11], among others.

The whole impact of ADHD can be better understood by extending the analysis of its severity in daily life functioning. The studies included in the systematic review by Agarwal et al. [12] showed that ADHD is associated with significant, adverse functional 
impairments and poor quality of life (QoL). Subsequent studies have confirmed this association, detecting greater difficulties in social functioning, couple relationships, work difficulties, personal finances, mood/temper control, self-organization and planning, and rule-breaking behavior [13]. The negative impact of ADHD on QoL occurs regardless of the academic level [14]. Even compared to adults with other psychiatric disorders, the daily life functioning and QoL of adults with ADHD is more impaired [15].

ADHD is one of the most heritable of psychiatric disorders, with a degree of hereditability of around $80 \%$ [16], although the gene-environment interaction must be taken into account in the explanation of its developmental course. Therefore, the analysis of follow-up studies provides information about childhood cognitive, behavioral, and family factors that can influence long-term outcomes in individuals with ADHD.

\subsection{Family Factors}

Based on evidence from longitudinal studies, sociodemographic characteristics, parents' psychopathology, the parental discipline style, and parenting stress seem to influence the persistence and course of ADHD. Low income levels, parental education, and family socioeconomic status $[17,18]$ predict the diagnostic stability of ADHD, and they are potential moderators of the prognosis in young adulthood [19] In addition, socio-economic disadvantage has an influence on the trajectory of ADHD, determining the level and growth of emotional and behavioral problems [20]. However, other studies found no associations between family socioeconomic status and ADHD persistence in adulthood or late adolescence [21,22].

The parents' psychopathology, and particularly the mother's vulnerability to depression [23], is also an important predictor of ADHD course over time. In a large 11-year follow-up study, ADHD persistence was associated with severe impairment and psychiatric comorbidity in children, as well as maternal psychopathology at baseline [24]. In addition to predicting the persistence of ADHD, the mother's self-reported depression influences the later development of conduct disorder symptoms [25].

Childhood ADHD symptoms interact with the parenting discipline style in predicting externalizing behavior in adolescence and early adulthood. Higher levels of mothers' authoritarian parenting during childhood have been associated with delinquent behavior in adolescent girls with higher levels of childhood hyperactivity and impulsivity (H/I) symptoms [26]. According to a longitudinal study, a child's age modulates the contribution of the discipline style and parental involvement to the level of $\mathrm{H} / \mathrm{I}$ at early and middle childhood. High parental involvement was related to lower H/I symptoms over time, but only at early childhood (children aged 5.11). In older children, the levels of H/I only increased at mid-childhood (children aged 7.8) by exposure to inconsistent discipline, probably due to a disruption in environmental contingencies [27]. In addition, parental criticism is associated with different ADHD trajectories, so that the highly persistent hyperactive group during the transition from childhood to adolescence is more likely to have parents with high criticism, compared to the other groups with ADHD [28].

Empirical data show that parents of children with ADHD experience high levels of daily stress [29]. The link between childhood ADHD and externalizing and internalizing symptoms in adulthood has been found to be mediated by the mother's stress [30]. Furthermore [31], maternal stress was found to be a risk factor for poor quality of life (QoL) in children with ADHD. Nevertheless, as the systemic perspective states, the relationships between the parenting style and ADHD are complex and have a bidirectional effect [32], so that greater maternal overreactive parenting and stress predicted more child ADHD symptoms, and, in turn, greater child ADHD symptoms significantly predicted higher maternal stress and depressive symptoms [33].

\subsection{Behavior Problems and Symptom Severity Factors}

According to the preschool attention deficit hyperactivity disorder treatment study (PATS) [34], comorbidity of oppositional defiant disorder (ODD) and/or conduct disorder 
was associated with a 30\% higher risk of having an ADHD diagnosis at the six-year followup. It has also been proven that the persistence of the disorder can be predicted by baseline ADHD severity and ODD severity [35]. Another study [36] analyzed a wide range of risk factors for negative outcomes at 18 years old, in terms of ADHD symptoms, overall functioning, and mental health disorders. Childhood predictors included pre/perinatal factors, child clinical characteristics, and aspects of the family environment. The remarkable conclusion was that the severity of childhood ADHD symptoms and lower IQ explained the persistence of the disorder at 18 years of age.

The severity of ADHD symptoms has also shown a negative association with measures of quality of life (QoL) [37]. It predicted social problems even when controlling for parenting behavior, the child's age and sex, and ODD symptoms [38]. Examining an extensive set of factors, ADHD symptom severity has proven to be the strongest predictor of adult outcomes, with weaker effects of IQ and household income [22].

\subsection{Neurocognitive Factors}

A systematic review with 18 studies concluded that persisters and remitters did not differ on neurocognitive functions, although both groups had worse performance than controls [39]. More recent studies found the same general tendency. Childhood severity of ADHD and actigraph movement predicted later outcomes, whereas other cognitive measures, such as Go/No-Go, Fast Task, and Index of Delay Aversion, did not have predictive power [19]. The results of a six-year follow-up study [40] showed that early neurocognitive functioning (working memory and reaction time variability) seemed to have a small positive influence on ADHD outcomes. Finally, another study [41] broadened the domains of the predictors by including measures of executive functions, parental stress, parenting discipline styles, and child psychopathology in the baseline. Two and a half years later, the children were classified as having persistent, remittent, or contextually persistent ADHD. The between-group comparison showed that the persistent groups had significantly more emotional lability and higher parental stress, whereas no differences in EF baseline measures were found between the persistent and remitted groups.

In summary, the findings of the longitudinal research suggest the involvement of a variety of factors in the persistence and course of ADHD, including socioeconomic disadvantage, parental psychopathology, or an inappropriate disciplinary style, as well as ADHD severity, psychiatric comorbidities, and, to a lesser degree, EF. However, studies have mainly used global measures to evaluate the results in the follow-up, rather than measures from specific domains of socio-personal adaptation. This more specific approach is essential for establishing specific consequences of ADHD that extend into adulthood. The aims of the current study, which is part of a longitudinal study following the trajectory of children with an ADHD diagnosis, were twofold: (1) to examine the association between early family, cognitive, and behavioral factors and long-term results in general impairment, EF, ADHD symptoms, and quality of life in individuals with childhood ADHD; and (2) to explore the contribution of early factors identified as the most significant in predicting general impairment, EF, ADHD symptoms, and quality of life of individuals with childhood ADHD.

\section{Materials and Methods}

\subsection{Participants}

In this follow-up study, the participants were 61 young adults with a childhood diagnosis of attention deficit hyperactivity disorder (ADHD) drawn from the Spanish sample of the International Multicenter ADHD Genetics (IMAGE) study, recruited between 2003 and 2006. The clinical diagnosis was performed by neuropediatricians and clinical psychologists, based on combining information from the Parental Account of Childhood Symptoms interview and the DSM-IV items on Conners' parent and teacher questionnaires. Exclusion criteria included a diagnosis of autism, epilepsy, IQ < 70, or brain disorders [42]. 
At baseline, the age range of the 61 children with ADHD was between 6 and 12 years old (Mean: 8.7). All of them had an intellectual capacity within the parameters of normality (Mean: 105.9), estimated by the sum of the scale scores for Vocabulary and Block Design on the Wechsler Intelligence Scale for children-Revised (WISC-R) [43]. In addition, the presence of psychopathologies in childhood was identified by using the Conners' rating Scales-Revised (CRS-R:L) completed by the parents [44]. The findings showed that $95.1 \%$ of the sample manifested cognitive problems of attention, $65.6 \%$ oppositionism, $49.2 \%$ social problems, $44.3 \%$ emotional disability, and a smaller percentage, $18 \%$, problems with anxiety and shyness. At baseline, less than $50 \%$ of children were receiving psychopharmacological treatment $(44.3 \%)$ or psychological treatment $(42.6 \%)$.

On average, 12 years after baseline, 61 children from the IMAGE Project sample collaborated in the current follow-up study between 2013 and 2017 (retention rate of $75.31 \%)$. According to the parents' and teachers' ratings on the DSM-total, there were no differences in ADHD severity between the 61 children who continued in the follow-up and the 20 who did not. Specifically, 13 participants could not be located, and seven participants declined the invitation to attend the evaluations.

The age of the participants ranged from 18 to 24 years. The intellectual level was within the normal range, evaluated with two subtests of the Wechsler Adult Scale [45]. In the follow-up, a high percentage of young adults were receiving pharmacological (83\%) and/or psychological treatment (71.1\%). According to the information obtained from Conners' Adult ADHD Rating Scales (CAARS-Self-rating form) [46], 43.9\% of the sample presented cognitive problems, and a smaller percentage, $17.5 \%$, had emotional lability. In terms of academic performance, $85.2 \%$ of the ADHD participants had repeated at least one grade during their educational stage. Moreover, $60.6 \%$ had completed secondary education, $29.5 \%$ primary education, and only $9.8 \%$ had completed upper secondary education (high school) or superior level vocational training.

Among the family characteristics, it should be noted that the average age of both parents was around 50 years, and $70.5 \%$ lived as a couple. The educational level presented variability: $45.9 \%$ had basic studies, $34.4 \%$ had studies equivalent to vocational training or high school, and $19.7 \%$ had university studies (See Table 1).

Table 1. Socio-demographic characteristics.

\begin{tabular}{|c|c|c|c|c|}
\hline Children & $\begin{array}{c}\text { Baseline } \\
(n=61)\end{array}$ & $\begin{array}{l}\text { Follow Up } \\
\quad(n=61)\end{array}$ & Family Characteristics & \\
\hline Age & $8.7(1.9)$ & $18.7(1.3)$ & Age mother & $49.7(4.3)$ \\
\hline $\mathrm{IQ}$ & $105.9(16.4)$ & $105.2(15.8)$ & Age father & $53.6(6.3)$ \\
\hline Gender (\% Males) & $95.1 \%$ & $95.1 \%$ & Family structure & \\
\hline Medication (\% yes) & $44.3 \%$ & $83 \%$ & Two parents $(\%)$ & 70.5 \\
\hline Psychological trea & yes) $42.6 \%$ & $72.1 \%$ & One parent $(\%)$ & 29.5 \\
\hline \multicolumn{2}{|c|}{ Psychopathology $(\% \mathrm{~T} \geq 63)$} & & Educational Level & \\
\hline Oppositionism & $65.6 \%$ & & Lower Secondary (\%) & 45.9 \\
\hline Anxious-shy & $18 \%$ & & Upper Secondary (\%) & 34.4 \\
\hline Social problems & $49.2 \%$ & & University studies (\%) & 19.7 \\
\hline Cognitive problems & $95.1 \%$ & $43.9 \%$ & Occupational status m (\% active) & $79.2 \%$ \\
\hline Emotional lability & $44.3 \%$ & $17.5 \%$ & Occupational status $\mathrm{f}(\%$ active) & $83.1 \%$ \\
\hline Conners' Global Index & $95.1 \%$ & $41.2 \%$ & & \\
\hline
\end{tabular}

\subsection{Baseline Measures}

\subsubsection{ADHD Symptoms and Children's Problem Behaviors}

Conners' Rating Scales-Revised, long version (CRS-R:L) [44]). This instrument has been validated for children and adolescents between three and 17 years old. It collects information about ADHD symptomatology and associated disorders, and it has shown acceptable validity and reliability. There are two versions, one for parents (CPRS-R:L) and the other for teachers (CTRS-R:L), containing 80 and 59 items, respectively, rated on a 4-point Likert-type scale ( 0 for never and 3 for very often). Of the 13 scales contained in the 
parents' version, the scales selected for the present study were oppositionism, the emotional lability index, and the scales related to the DSM-IV-TR diagnosis of ADHD (inattention and hyperactivity-impulsivity). From the teachers' version, only the last three scales were chosen, which included ADHD criteria according to the DSM-IV-TR. Evidence for the short form's internal consistency, test-retest reliability, and factorial validity is provided in the manual [44].

\subsubsection{Family Characteristics}

Sociodemographic characteristics. Information was collected through a semi-structured interview about age, gender, marital status (cohabitants/married or single, divorced/widowed), parents' education (compulsory school, upper secondary school, or college/university), place of residence (urban or rural), and maternal reported diagnosis of depression disorder.

Parenting Scale [47]. This 30-item questionnaire measures parents' dysfunctional discipline styles by asking about the probability of the parent using specific discipline strategies in response to the child's misbehavior. For each item, using a seven-point Likert scale, the parents have to choose the number that best describes the parenting style used with their child during the past two months, where 1 indicates a high probability of using an effective discipline strategy and 7 indicates a high probability of using an ineffective strategy. The Parenting Scale contains three subscales: Laxness, which includes 11 items reflecting permissive, inconsistent discipline ("When I say my child can't do something ... I let my child do it anyway"); Over-reactivity, which has 10 items related to displays of anger, meanness, and irritability (When my child misbehaves ... I raise my voice or yell"); and verbosity, which includes seven items about wordy responses to the child ("I threaten to do things that ... I'm sure I can carry out"). Both Laxness and Overreactivity had adequate internal consistency and good test-retest reliability. Verbosity had lower internal consistency. The scale has adequate reliability (0.84) and discriminates between parents of clinical and non-clinical children. It correlates with self-report measures of child behavior, marital discord, and depressive symptoms, and also with observational measures of dysfunctional discipline and child behavior [47].

Parenting Stress Index (PSI) [48]. This self-report questionnaire, that assesses parenting stress, includes 101 items rated on a 5-point Likert-type scale. The items on the PSI are distributed in six subscales that measure the characteristics of the child that make childrearing difficult and can be the source of parental stress (distractibility/hyperactivity, adaptability, reinforces parent, demandingness, mood, acceptability) and seven subscales that measure characteristics of the parents that can interfere with adequately performing their parental role (depression, sense of competence, role restriction, isolation, attachment, health, and spousal support). The PSI provides a score for each variable and a global score for each domain (child and parent). In addition, it provides a total stress score (Total Stress Index). The reliability, validity, and normative properties of the PSI are included in the manual for this test, with internal consistency indices of around 0.90 [48].

Sense of Coherence (SOC) [49]. The SOC questionnaire includes 29 items that capture three dimensions, namely, manageability, meaningfulness, and comprehensibility, which are all closely interrelated (e.g., "How often do you feel that there is no meaning to the things you do every day?"). The items are rated on a seven-point Likert scale, with the highest scores indicating a high level of sense of coherence. In this study, the SOC total score was used. The SOC has shown excellent internal consistency $(\alpha=0.88)$ and evidence of external validity [50].

\subsubsection{Neuropsychological Functions}

Four domains of executive functioning were evaluated: verbal memory, visuo-spatial working memory, attention, and inhibition.

Verbal memory was assessed with the WISC-R Digit-Span Subtest [43], which includes two parts: Digits Forward primarily taps short-term auditory memory, whereas Digits Backward measures the child's ability to manipulate verbal information in temporary storage. 
Visuo-spatial working memory was evaluated with the Temporo-Spatial Retrieval Task (TSRT; [51]), a computerized task consisting of 30 trials organized in two phases. The first phase involves a stimuli presentation stage in which the child is asked to pay attention to 12 blue squares distributed randomly on the screen that sequentially change to the color red. In the second response phase, the squares are again presented on the screen, and the child must point to them with his/her finger, following the sequence in which they changed color. Specifically, the score obtained on the delayed recall condition (where a black screen appears for $1500 \mathrm{msec}$. between the two phases, increasing the demands on working memory) was used.

The computerized continuous performance task CPT AX version (CPT-AX) [52] was applied to evaluate inhibition and attention. On this task, which has a duration of eight minutes, white capital letters are randomly and successively presented every $600 \mathrm{msec}$. $(\mathrm{A}, \mathrm{B}, \mathrm{F}, \mathrm{G}, \mathrm{H}, \mathrm{J}, \mathrm{K}, \mathrm{N}, \mathrm{T}, \mathrm{V}, \mathrm{X})$ at the center of the screen on a black background. The child must respond by pressing the space bar on the computer keyboard as fast as possible every time he/she sees an X preceded by an A, which occurs 50 times. The inhibition indicator used consisted of the errors of commission (pressing the space bar when only the A appears, or only the $X$, or any other stimulus different from the AX association). The number of omission errors was used as an index of attention.

\subsection{Follow-Up Measures}

\subsubsection{ADHD Symptoms and Associated Behaviors}

Conners' Adult ADHD Rating Scales, Long Version (CAARS) [46]. This self-rated long version of the CAARS consists of 66 statements rated on a scale from 0 to 3 ( 0 for not at all, never, and 3 for very much, quite frequently). Eight cluster scales are derived from these items. Three of these scales correspond exactly to the DSM-IV diagnostic criteria for ADHD, whereas the other five scales index behaviors that have been associated with ADHD but were not specifically defined in the DSM-IV criteria: Inattentive behaviors; Hyperactive behaviors; Impulsive/emotional lability; Self-Concept problems; and Conners' ADHD Index. T-scores are calculated for each scale based on age and gender. Our study focused on the ADHD Index scale, with higher scores indicating more severe symptomatology. Test-retest reliability and validity of the CAARS have been found to be acceptable [46]. Moreover, the $\alpha$ coefficient of 0.85 for the overall ADHD Index subscale in our sample was adequate.

\subsubsection{Quality of Life}

The self-report Quality of Life Enjoyment and Satisfaction Questionnaire (Q-LESQ) [53] was used to easily obtain sensitive measures of the degree of enjoyment experienced by individuals in various areas of daily functioning. It contains 93 items that collect information in the areas of physical health, mood, work, school activities, leisure time activities, social relationships, and general activities. The general activities scale applied in our study asks the individual to evaluate, using a five-point Likert scale (from 1 = very poor to 5 = very good), the satisfaction experienced in 16 different aspects in the past week. This instrument has high internal consistency (0.88) and convergent validity with social adjustment (0.72) [54]. In our sample, the internal consistency of the general activities scale was adequate $(\alpha=0.81)$.

\subsubsection{Functional Impairment}

Weiss Functional Impairment Rating Scale Self-report, WFIRS-S [55]. This self-report instrument includes 69 items rated on a four-point Likert-type scale with responses ranging from never or not at all to very often or very much. The items cover the subdomains of family ("Causing fighting in the family"), school, life skills ("Problems managing money"), self-concept ("Feeling frustrated with yourself"), social activities ("Trouble getting along with people"), and risk activities ("Breaking or damaging things"). In our study, the work subscale was not included due to the low number of subjects who were working at the time 
of the evaluation. The psychometric properties of the WFIRS-S, including construct validity, internal structural validity, and external validity, have been tested in several studies [56,57]. Cronbach's alpha coefficients obtained for the overall scale have been high (0.91). In the present study, the $\alpha$ coefficient was 0.85 for the total scale. The $\alpha$ coefficient value for the rest of the scales ranged from risky activities $=0.81$ to life skills $=0.70$.

\subsubsection{Executive Function}

The Behavior Rating Inventory of Executive Functions-Adult version [58], BRIEFA, was used to obtain self-reports of cognitive, behavioral, and emotional EF from the participants in everyday situations. Items on the BRIEF-A are rated on a three-point scale (never, sometimes, often) and grouped into nine factorial subscales: inhibit, shift, emotional control, self-monitor, initiate, working memory, planning/organize, task monitor, and organization of materials. The nine subscales form two separate indexes, the behavioral regulation index (BRI) and the metacognition index (MI). These indexes form the overall summary score, the Global Executive Composite (GEC), with higher scores indicating greater EF impairment in daily life. The BRIEF-A has adequate test-retest reliability (correlations ranging from 0.82 to 0.94 ) and internal consistency ( $\alpha$ coefficients ranging from 0.85 to 0.98 ), as well as convergent and discriminant validity [58]. The $\alpha$ coefficient for the GEC used in this study was 0.86 .

\subsection{Procedure}

The information about follow-up measures was collected through questionnaires completed by adult participants with ADHD in an office with optimal conditions in the School Psychology at the University of Valencia. The assessment was performed by ADHD experts trained in the administration and rating of the questionnaires used. All the participants gave their written consent after being informed of the study goals and funding before beginning the first evaluation session. All procedures were performed following the ethical standards of the Ethics Committee of the University of Valencia (Procedure number HI493972644643), according to the principles of the Helsinki Declaration of the World Medical Association [59].

\subsection{Data Analyses}

The statistical analyses were performed with the statistical program for the Social Sciences (SPSS), version 24. Preliminary analyses were conducted to examine the distribution of the variables using the Kolmogorov-Smirnov test; variables that did not show a normal distribution were transformed using square-root transformation.

Pearson correlations were calculated to examine the relationship between early family, behavioral, and neuropsychological factors and follow-up functional outcomes such as the total WFIRS-S, Q-LES-Q, executive functions, and CAARS total index in adults with ADHD. Finally, multiple linear regression analyses were conducted to test the effect of family factors (Depression, Educational level, Laxness, Overreactivity, Coherence, and PSI), behavioral factors (Oppositionism, Emotional lability, Inattention, Hyperactivity-Impulsivity), and neuropsychological factors on the four functional outcomes: total WFIRS-S, Q-LES-Q, executive functions, and CAARS total index (dependent variables).

\section{Results}

\subsection{Relationships between Family, Cognitive, and Behavioral Factors and Follow-Up Outcomes}

Table 2 shows Pearson correlation analyses between the early family, behavioral, and neuropsychological factors and the follow-up functional outcomes in ADHD adults. Specifically, with regard to Family factors, Depression significantly correlated with the EF-GEC from the BRIEF-A scale $(p<0.001)$ and the total CAARS index $(p<0.001)$. Similarly, Laxness significantly correlated with the total WFIRS $(p=0.007)$, EF-GEC $(p<0.001)$, and the CAARS $(p=0.012)$. There were also significant correlations between parenting 
coherence and the CAARS $(p=0.013)$. Finally, the parenting stress index significantly correlated with quality of life $(p=0.018)$.

Table 2. Correlations between early family, behavioral, and neuropsychological factors and follow-up functional outcomes in attention deficit hyperactivity disorder (ADHD) adults.

\begin{tabular}{|c|c|c|c|c|c|}
\hline Early Factors & & Total WFIRS-S & Q-L-Q Total & EF-GEC BRIEF & CAARS T. Index \\
\hline \multirow{6}{*}{ Family } & Depression & 0.061 & -0.226 & $0.338^{* *}$ & $0.349^{* *}$ \\
\hline & Educational L & 0.090 & 0.098 & 0.05 & 0.149 \\
\hline & Laxness & $0.312 *$ & -0.115 & $0.470 * *$ & 0.279 * \\
\hline & Overreactivity & 0.182 & 0.001 & 0.251 & 0.207 \\
\hline & P. Coherence & 0.091 & 0.094 & -0.156 & $-0.295^{*}$ \\
\hline & PSI total & 0.180 & $-0.259 *$ & 0.237 & 0.233 \\
\hline \multirow{4}{*}{ Behavioral } & Oppositionism & 0.110 & $-0.281 *$ & $0.401 * *$ & $0.374^{* *}$ \\
\hline & E. Lability & 0.149 & $-0.265^{*}$ & $0.294 *$ & 0.209 \\
\hline & Inattention & 0.101 & -0.216 & $0.344^{* *}$ & 0.186 \\
\hline & H-I & 0.013 & -0.205 & 0.136 & $0.282 *$ \\
\hline \multirow{5}{*}{ Neuropsychological } & DIGIT_Direct & 0.076 & 0.176 & 0.192 & 0.089 \\
\hline & DIGIT_reverse & 0.068 & -0.09 & 0.199 & 0.11 \\
\hline & T. Temporo & 0.077 & -0.091 & 0.264 * & 0.201 \\
\hline & CPT Omissions & 0.166 & 0.032 & -0.019 & 0.012 \\
\hline & CPT Commission & 0.163 & 0.075 & -0.144 & -0.238 \\
\hline
\end{tabular}

${ }^{*} p<0.05,{ }^{* *} p<0.01$; Notes: WFIRS (Weiss Functional Impairment Rating Scale), E. Lability (Emotional Lability), H-I (hyperactivity/impulsivity), CPT (Continuous Performance Task), EF-GEC (Executive function Global Executive Composite), Q-L-Q (Quality of life), CAARS T. (Conners' Adult ADHD Rating Scale Total score), Educational L (Educational level), P. Coherence (parenting coherence), PSI (Parenting Stress Index).

Based on cognitive/behavioral factors and follow-up functional outcomes in ADHD adults, results showed that quality of life significantly correlated with oppositionism $(p=0.003)$ and emotional lability $(p=0.006)$. Similarly, the EF-GEC significantly correlated with the following behavioral factors: total oppositionism $(p<0.001)$, emotional lability $(p=0.002)$, and inattention $(p<0.001)$, and with one neuropsychological variable, visuo-spatial working memory-Temporo $(p=0.007)$. There were also significant correlations between the CAARS and oppositionism $(p<0.001)$ and hyperactivity/impulsivity $(p=0.006)$.

\subsection{Family, Cognitive, and Behavioral Predictors of Follow-Up Outcomes}

Separate multiple regressions were conducted to study whether early family factors and children's behavioral/neuropsychological factors were related to different ADHD adult functional outcomes (see Tables 3-5).

The regression analyses conducted with the family factors indicated that depression was a significant individual predictor of quality of life $(\beta=-0.37, p=0.02)$, total executive function-EF-GEC $(\beta=0.43, p<0.000)$, and total CAARS $(\beta=0.53, p<0.000)$. The family factor PSI index was a significant predictor of quality of life $(\beta=-0.37, p=0.03)$ and total CAARS $(\beta=0.28, p=0.05)$. Finally, laxness was a significant individual predictor of total executive function-EF-GEC $(\beta=0.41, p=0.01)$. All the predictors collectively explained $41 \%$ and $39 \%$ of the variance in EF-GEC and Total CAARS, respectively (Table 3 ).

In the case of the behavioral factors, oppositionism was an individual predictor of Total CAARS $(\beta=0.39, p=0.02)$, explaining $17 \%$ of the variance. There was no unique individual predictor of the EF-GEC, but together the early family factors explained $20 \%$ of its variance (Table 4$)$.

Regarding the neuropsychological factors, DIGIT direct was a significant individual predictor of Quality of life $(\beta=0.28, p=0.05)$, and CPT commissions were a significant individual predictor of

Total CAARS $(\beta=-0.32, p=0.02)$. All the predictors collectively explained $8 \%$ and $13 \%$ of the variance in the EF-GEC and Total CAARS, respectively (Table 5). 
Table 3. Multiple regressions for early family factors predicting different adult functional outcomes.

\begin{tabular}{|c|c|c|c|c|c|c|c|c|c|c|c|c|c|c|}
\hline Family Factors & Beta & $\mathbf{t}$ & $\mathbf{P}$ & $\mathbf{R}$ & $\mathbf{R}^{2}$ & F & $\mathbf{P}$ & Beta & $\mathrm{t}$ & $\mathbf{P}$ & $\mathbf{R}$ & $\mathrm{R}^{2}$ & F & $\mathbf{P}$ \\
\hline & & Total Wfirs & & 0.31 & 0.09 & 0.77 & 0.59 & & QLQ & & 0.48 & 0.23 & 2.13 & 0.06 \\
\hline Depression & 0.05 & 0.31 & 0.75 & & & & & -0.37 & -2.35 & $0.02 *$ & & & & \\
\hline Educational L & 0.08 & 0.47 & 0.64 & & & & & 0.28 & 1.78 & 0.08 & & & & \\
\hline Laxness & 0.18 & 1.01 & 0.31 & & & & & 0.01 & 0.04 & 0.97 & & & & \\
\hline Overreactivity & 0.07 & 0.43 & 0.66 & & & & & -0.02 & -0.13 & 0.90 & & & & \\
\hline P. Coherence & 0.12 & 0.69 & 0.49 & & & & & 0.20 & 1.20 & 0.24 & & & & \\
\hline PSI total & 0.09 & 0.57 & 0.57 & & & & & -0.37 & -2.31 & $0.03 *$ & & & & \\
\hline & & EF-GEC & & 0.64 & 0.41 & 5.10 & $0.000 *$ & & T.CAARS & & 0.62 & 0.39 & 4.57 & 0.001 * \\
\hline Depression & 0.43 & 3.09 & 0.00 * & & & & & 0.53 & 3.80 & $0.00 *$ & & & & \\
\hline Educational L & -0.02 & -0.13 & 0.90 & & & & & -0.02 & -0.14 & 0.89 & & & & \\
\hline Laxness & 0.41 & 2.84 & $0.01 *$ & & & & & 0.14 & 0.94 & 0.35 & & & & \\
\hline Overreactivity & 0.08 & 0.60 & 0.55 & & & & & 0.16 & 1.15 & 0.26 & & & & \\
\hline P. Coherence & 0.16 & 0.09 & 0.28 & & & & & 0.24 & 1.61 & 0.11 & & & & \\
\hline PSI total & 0.18 & 1.28 & 0.21 & & & & & 0.28 & 1.99 & $0.05 *$ & & & & \\
\hline
\end{tabular}

* $p<0.05$; Notes: WFIRS (Weiss Functional Impairment Rating Scale), Educational L (Educational level), P. Coherence (parenting coherence), PSI (parenting stress index), EF-GEC (Executive function Global Executive Composite), QLQ (Quality of life), T. CAARS (Total Conners' Adult ADHD Rating Scale).

Table 4. Multiple regressions for children's behavioral factors predicting different adult functional outcomes.

\begin{tabular}{|c|c|c|c|c|c|c|c|c|c|c|c|c|c|c|}
\hline $\begin{array}{c}\text { Behavioral } \\
\text { Factors }\end{array}$ & Beta & $\mathbf{t}$ & $\mathbf{P}$ & $\mathbf{R}$ & $\mathbf{R}^{2}$ & $\mathbf{F}$ & $\mathbf{P}$ & Beta & $\mathbf{t}$ & $\mathbf{P}$ & $\mathbf{R}$ & $\mathbf{R}^{2}$ & $\mathbf{F}$ & $\mathbf{P}$ \\
\hline & \multicolumn{3}{|c|}{ Total WFIRS } & 0.25 & 0.05 & 0.74 & 0.56 & & QLQ & & 0.32 & 0.10 & 1.65 & 0.17 \\
\hline Oppositionism & 0.10 & 0.55 & 0.58 & & & & & -0.12 & -0.70 & 0.48 & & & & \\
\hline E. Lability & 0.12 & 0.73 & 0.46 & & & & & 0.13 & 0.76 & 0.45 & & & & \\
\hline Inattention & 0.19 & 1.24 & 0.22 & & & & & 0.08 & 0.56 & 0.57 & & & & \\
\hline \multirow[t]{2}{*}{ H-I } & 0.02 & 0.12 & 0.90 & & & & & -0.08 & -0.56 & 0.57 & & & & \\
\hline & \multicolumn{3}{|c|}{ EF-GEC } & 0.45 & 0.20 & 3.55 & $0.012 *$ & & T.CAARS & & 0.41 & 0.17 & 2.92 & 0.029 * \\
\hline Oppositionism & 0.28 & 1.63 & 0.10 & & & & & 0.39 & 2.25 & $0.02 *$ & & & & \\
\hline E. Lability & 0.06 & 0.41 & 0.68 & & & & & 0.10 & 0.61 & 0.54 & & & & \\
\hline Inattention & 0.24 & 1.68 & 0.09 & & & & & 0.05 & 0.34 & 0.73 & & & & \\
\hline H-I & -0.09 & -0.66 & 0.51 & & & & & 0.19 & 1.41 & 0.16 & & & & \\
\hline
\end{tabular}

${ }^{*} p<0.05$; Notes: E. Lability (Emotional Lability), H-I (hyperactivity/impulsivity), EF-GEC (Executive function Global Executive Composite), QLQ (Quality of life), T. CAARS (Total Conners' Adult ADHD Rating Scale.

Table 5. Multiple regressions for children's neuropsychological factors predicting different adult functional outcomes.

\begin{tabular}{|c|c|c|c|c|c|c|c|c|c|c|c|c|c|c|}
\hline $\begin{array}{l}\text { Neuropsychological } \\
\text { Factors }\end{array}$ & Beta & $\mathbf{t}$ & $\mathbf{P}$ & $\mathbf{R}$ & $\mathbf{R}^{2}$ & $\mathbf{F}$ & $\mathbf{P}$ & Beta & $\mathbf{t}$ & $\mathbf{P}$ & $\mathbf{R}$ & $\mathbf{R}^{2}$ & $\mathbf{F}$ & $\mathbf{P}$ \\
\hline & \multicolumn{3}{|c|}{ Total WFIRS } & 0.21 & 0.04 & 0.52 & 0.75 & & QLQ & & 0.28 & 0.08 & 1.00 & 0.42 \\
\hline DIGIT_Direct & 0.03 & 0.24 & 0.80 & & & & & 0.28 & 1.96 & $0.05 *$ & & & & \\
\hline DIGIT_reverse & 0.06 & 0.38 & 0.70 & & & & & -0.20 & -1.20 & 0.23 & & & & \\
\hline T. Temporo & 0.08 & 0.61 & 0.54 & & & & & -0.10 & -0.78 & 0.43 & & & & \\
\hline CPT Omission & -0.13 & -0.79 & 0.42 & & & & & -0.04 & -0.26 & 0.79 & & & & \\
\hline \multirow[t]{2}{*}{ CPT Commiss } & -0.10 & -0.72 & 0.47 & & & & & 0.09 & 0.63 & 0.53 & & & & \\
\hline & \multicolumn{3}{|c|}{ EF-GEC } & 0.36 & 0.13 & 1.73 & 0.14 & & T.CAARS & & 0.36 & 0.13 & 1.67 & 0.15 \\
\hline DIGIT_Direct & 0.10 & 0.73 & 0.46 & & & & & 0.02 & 0.15 & 0.87 & & & & \\
\hline DIGIT_reverse & 0.18 & 1.09 & 0.27 & & & & & 0.12 & 0.73 & 0.46 & & & & \\
\hline T. Temporo & 0.22 & 1.74 & 0.08 & & & & & 0.18 & 1.43 & 0.15 & & & & \\
\hline CPT Omission & 0.19 & 1.17 & 0.24 & & & & & 0.24 & 1.44 & 0.15 & & & & \\
\hline CPT Commiss & -0.17 & -1.2 & 0.21 & & & & & -0.32 & -2.24 & $0.02 *$ & & & & \\
\hline
\end{tabular}

* $p<0.05$; Notes: CPT (Continuous Performance Task), EF-GEC (Executive function Global Executive Composite), QLQ (Quality of life), T.

CAARS (Total Conners' Adult ADHD Rating Scale, WFIRS (Weiss Functional Impairment Rating Scale).

\section{Discussion}

The first aim of the present study was to examine the relationship between early family, cognitive, and behavioral factors and long-term outcomes of individuals with childhood ADHD in the areas of EF impairments, ADHD symptoms, and quality of life.

Maternal depression and the discipline style characterized by laxness were found to be the factors in the family context that had the most significant relationships with the 
functioning outcomes of children with ADHD as young adults. After 12 years, maternal depression maintained a positive association with ADHD symptoms and a negative association with executive functioning. The results of our study not only showed the relationship between maternal psychopathology and the persistence of ADHD symptoms, as in other previous studies [24,25], but they also showed an association between maternal depression and the child's EF impairments. This finding joins the results of longitudinal studies with children with typical development, showing that exposure to high maternal depression symptoms during the child's early years is associated with lower EF [60,61]. Likewise, a parenting discipline style of laxness, characterized by behaving in a permissive and inconsistent way with a tendency to avoid behavioral control or fail to set limits and enforce rules, is associated with functional impairments, ADHD symptom severity, and worse EF in adulthood. Other studies [27] have also found that aspects of parental performance that indicate a lack of involvement and are linked to a permissive parenting style contribute to the persistence of hyperactivity/inattention symptoms.

Although there are no antecedents in the literature to refer to, parents' sense of coherence has a negative relationship with ADHD symptoms. Comprehensible, manageable, and meaningful resources to cope with raising a child with ADHD had a favorable effect on the evolution of the symptoms of the disorder. By contrast, coinciding with a recent study [31], our study detected a negative relationship between the parents' stress during their offspring's childhood and the child's later quality of life in different areas of daily life, such as health, mood, work, leisure activities, or social relationships. Clearly, the experiences of exhaustion, anxiety, and helplessness associated with caring for a child with ADHD provoke high levels of daily stress, eroding the family's overall quality of life. However, coinciding with various studies [21,22], the parents' educational level is not associated with any of the variables used as outcome measures in ADHD adults. The homogeneity in the academic status of the participants' parents might partly explain the lack of relationship.

In the block of characteristics related to the child's behavior, the scores on oppositionism and emotional lability stand out. Thus, the oppositionist behaviors rated by the parents in childhood, which are highly comorbid with ADHD, maintained a significant relationship with three of the four outcome measures 12 years later: the ADHD index, quality of life, and EF. As in previous longitudinal studies [24,62], our study also supported the significant relationship between ADHD symptoms and oppositionist behaviors in childhood and the persistence of ADHD symptoms in adulthood. Another interesting result was the significant relationship between the oppositionism of the participants with ADHD in childhood and lower QoL in adulthood, which indicates that the evolution of ADHD is complicated by the presence of oppositionist behaviors [63]. Finally, emotional lability, which affects a representative number of individuals with ADHD [64] and is usually linked to impairments in most clinical areas [65], showed a significant association with quality of life and overall EF. The significant role of emotional lability in EF in adulthood would be expected, given that the EF measures used in our study incorporate aspects of emotional dysregulation in daily life, including inhibition, shifting, and emotional control, thus focusing the influence of executive functions on the expression and regulation of emotions.

Our second aim was to use regression analysis to explore the contribution of the most significant early factors in each block to the prediction of general impairment, EF, ADHD symptoms, and quality of life in individuals with childhood ADHD. With regard to the family factors, maternal depression emerged in the models as the most discriminating variable in the prediction of $\mathrm{EF}$, along with Laxness ( $\mathrm{R} 2=41 \%)$. Moreover, maternal depression and, to a lesser degree, parenting stress, was the variable with the most weight in predicting ADHD symptoms ( $2=39 \%$ ) and quality of life ( $R 2=23 \%$ ). The main idea to be highlighted is that characteristics of early home environments, including maternal depression, a lax discipline style, and parenting stress, were long-term predictors of ADHD symptom stability, EF impairments, and low quality of life. The effects of the family climate 
variable observed in our results are similar to those identified in previous longitudinal studies $[24,27,31,33,40]$.

Regarding the behavioral factors, oppositionism during childhood was the strongest predictor of diagnostic stability, measured with the ADHD Index, explaining $17 \%$ of the variance. As seen in previous studies, childhood oppositionism severity predicted the risk of adult symptom persistence [34]. Likewise, there was a significant $(p=0.012)$ predictive role of the set of variables that includes oppositionism, emotional lability, inattention, and hyperactivity/impulsivity at baseline in the degree of later EF $(R 2=20 \%)$. Therefore, the role played by all these variables as potential predictors of ADHD outcomes over time is supported [22,35-38]. Finally, the percentage of variance explained by the neuropsychological factors in the four regression analyses carried out was quite small ( $4 \%$ of impairment, $8 \%$ of quality of life, and $3 \%$ of EF and the ADHD index). Immediate recall and an inhibition indicator (CPT commissions) stood out, respectively, for their significance in the model predicting quality of life and ADHD symptoms in adulthood.

\section{Limitations and Practical Implications}

There were several limitations of the present study that must be considered. First, although it is frequent in studies with clinical ADHD samples, we had a small sample size, which could make it more difficult to identify relationships between the variables of interest. The probability of Type II errors is greater, and some null findings could therefore be related to a lack of statistical power. In addition, the participants were mainly males diagnosed with ADHD combined subtype, and so the results may not be completely applicable to other presentations of the disorder or to women. Another aspect to consider is that family factors in Spain may have different characteristics from those in other parts of the world, due to cultural factors. Moreover, our participants' families basically came from middle-low class families with no social marginalization; therefore, our findings may be more generalizable to the middle class. It is also important to consider the limitations related to the evaluation method. At baseline, the assessment of neuropsychological factors would have been more complete if it had included measures of planning, flexibility, and reaction time. Furthermore, the follow-up assessment was based on self-reports, which could be affected by social desirability bias. Finally, it should also be taken into account that the predictive value of the variables included in this study was moderate, which suggests that other variables are also important.

In spite of its limitations, this research extends the growing body of literature analyzing factors related to the evolution of ADHD. A recent systematic review of longitudinal studies on adults with a history of ADHD concluded that the majority of them experience more educational impairments and lower occupational attainment than their peers with negative implications in their quality of life [66]. Therefore, one of the important practical implications stemming from our findings is the need to explore, in educational and clinical settings, characteristics of the family context that influence the socio-personal adaptation of adults with a childhood ADHD diagnosis. The experts emphasize that the improvement of the communication between patients and mental health services and the school personnel is necessary for an effective ADHD treatment [67]. From a policy perspective, adopting this measure would require mobilizing community-wide resources.

The influence of maternal depression and parenting stress found in the long-term evolution of ADHD reveals that the families need support in coping with the many childrearing challenges they face. Parent counseling may have a potentially important role in early ADHD treatment. There is reliable assumption that children with ADHD use more avoidant-focused coping strategies than parents of typical development children [68]. Therefore, it would be necessary to explore coping mechanisms of such parents in order to promote positive coping strategies and to help them to identify people who can support them. Furthermore it would be necessary to help parents to decrease their stress levels, which are often associated with inadequate discipline styles and scant parental involvement. An emerging body of research suggests that cognitive restructuring and mindfulness can 
be effective in reducing parenting stress and depression symptoms in mothers of children with ADHD [69,70]. Therefore, some mindfulness parenting and cognitive restructuring principles could be applied within the framework of other strategies that have shown significant benefits, such as behavioral therapy for parents.

Author Contributions: A.M., C.B., B.R., F.M., and J.M.-R. designed and coordinated the study. B.R., J.M.-R., and C.B. participated in data collection. C.B. and B.R. helped to perform the data analysis. All authors participated in data interpretation and helped draft the manuscript. All authors have read and agreed to the published version of the manuscript.

Funding: This work was supported by a grant from the Consellería de Investigación y Ciencia de la Generalitat Valenciana (AICO/2018/198). The funder had no role in the study design, data collection, analysis, interpretation, writing of the report, or decision to submit the paper for publication.

Institutional Review Board Statement: Not applicable.

Informed Consent Statement: Not applicable.

Acknowledgments: We thank Faraone for inviting us to collaborate in the IMAGE project, and all the families and youths who kindly participated in this research.

Conflicts of Interest: The authors declare no conflict of interest.

\section{References}

1. Sibley, M.H.; Mitchell, J.T.; Becker, S.P. Method of adult diagnosis influences estimated persistence of childhood ADHD: A systematic review of longitudinal studies. Lancet Psychiatry 2016, 3, 1157-1165. [CrossRef]

2. Faraone, S.; Biederman, J.; Mick, E. The age-dependent decline of attention deficit hyperactivity disorder: A meta-analysis of follow-up studies. Psychol. Med. 2006, 36, 159-165. [CrossRef] [PubMed]

3. Kooij, J.J.S.; Bijlenga, D.; Salerno, L.; Jaeschke, R.; Bitter, I.; Balázs, J.; Thome, J.; Dom, G.; Kasper, S.; Nunes, F.C.; et al. Updated European consensus statement on diagnosis and treatment of adult ADHD. Eur. Psychiatry 2019, 56, 14-34. [CrossRef] [PubMed]

4. Cook, J.; Knight, E.; Hume, I.; Qureshi, A. The self-esteem of adults diagnosed with attention- deficit/hyperactivity disorder (ADHD). A Systematic Review of Literature. ADHD. Atten. Def. Hyper. Disord. 2014, 6, 249-268. [CrossRef] [PubMed]

5. Biederman, J.; Monuteaux, M.C.; Mick, E.; Spencer, T.; Wilens, T.E.; Silva, J.; Faraone, S.V. Young adult outcome of attention deficit hyperactivity disorder: A controlled 10-year follow-up study. Psychol. Med. 2006, 36, 167-179. [CrossRef] [PubMed]

6. Lin, Y.J.; Yang, L.K.; Gau, S.S. Psychiatric comorbidities of adults with early-and late-onset attention-deficit/hyperactivity disorder. Aust. N. Z. J. Psychiatry 2016, 50, 548-556. [CrossRef]

7. Storebo, O.J.; Simonsen, E. The Association between ADHD and Antisocial Personality Disorder (ASPD): A Review. J. Atten. Disord. 2016, 20, 815-824. [CrossRef] [PubMed]

8. Anker, E.; Bendiksen, B.; Heir, T. Comorbid psychiatric disorders in a clinical sample of adults with ADHD, and associations with education, work and social characteristics: A cross-sectional study. BMJ Open 2018, 8, e019700. [CrossRef]

9. Katzman, M.A.; Bilkey, T.S.; Chokka, P.R.; Fallu, A.; Klassen, L.J. Adult ADHD and comorbid disorders: Clinical implications of a dimensional approach. BMC Psychiatry 2017, 17, 302-327. [CrossRef]

10. Molina, B.S.; Howard, A.L.; Swanson, J.M.; Stehli, A.; Kennedy, T.L.; Epstein, J.; Arnold, E.; Hetchman, L.; Vitiello, B.; Hoza, B. Substance use through adolescence into early adulthood after childhood-diagnosed ADHD: Findings from the MTA longitudinal study. J. Child Psychol. Psych. 2018, 59, 692-702. [CrossRef]

11. Salomone, S.; Fleming, G.R.; Bramham, J.; O'Connell, R.G.; Robertson, I.H. Neuropsychological deficits in adult ADHD: Evidence for differential attentional impairments, deficient executive functions and high self-reported functional impairments. J. Atten. Disord. 2020, 24, 1413-1424. [CrossRef] [PubMed]

12. Agarwal, R.; Goldenberg, M.; Perry, R.; Ishak, W.W. The quality of life of adults with attention deficit hyperactivity disorder: A systematic review. Innov. Clin. Neurosc. 2012, 9, 10-21.

13. Pitts, L.; Mangle, P.; Asherson, P. Impairments, diagnosis and treatments associated with attention-deficit/hyperactivity disorder (ADHD) in UK adults: Results from the lifetime impairment survey. Arch. Psychiatr. Nurs. 2015, 29, 56-63. [CrossRef] [PubMed]

14. Pinho, T.D.; Manz, P.H.; DuPaul, G.J.; Anastopoulos, A.D.; Weyandt, L.L. Predictors and Moderators of Quality of Life Among College Students With ADHD. J. Atten. Disord. 2019, 23, 1736-1745. [CrossRef] [PubMed]

15. Holst, Y.; Thorell, L.B. Functional impairments among adults with ADHD: A comparison with adults with other psychiatric disorders and links to executive deficits. Appl. Neuropsychol. Adult 2020, 27, 243-255. [CrossRef] [PubMed]

16. Faraone, S.V.; Larsson, H. Genetics of attention deficit hyperactivity disorder. Mol. Psychiatry 2019, 24, 562-575. [CrossRef]

17. Kim, M.; King, M.; Jennings, J. ADHD remission, inclusive special education, and socioeconomic disparities. SSM Popul. Health 2019, 8, 100420. [CrossRef]

18. Law, E.C.; Sideridis, G.; Prock, L.A.; Sheridan, M.A. Attention-deficit/hyperactivity disorder in young children: Predictors of diagnostic stability. Pediatrics 2014, 133, 659-667. [CrossRef] 
19. Cheung, C.H.M.; Rijsdijk, F.; McLoughlin, G.; Brandeis, D. Cognitive and neurophysiological markers of ADHD persistence and remission. Br. J. Psychiatry 2015, 62, 92-100. [CrossRef]

20. Flouri, E.; Midouhas, E.; Charman, T.; Sarmadi, Z. Poverty and the Growth of Emotional and Conduct Problems in Children with Autism with and Without Comorbid ADHD. J. Autism Dev. Disord. 2015, 45, 2928-2938. [CrossRef]

21. Biederman, J.; Petty, C.R.; Woodworth, K.Y.; Lomedico, A.; Hyder, L.L.; Faraone, S.V. Adult outcome of attentiondeficit/hyperactivity disorder: A controlled 16-year follow-up study. J. Clin. Psychiatry 2012, 73, 941-950. [CrossRef] [PubMed]

22. Roy, A.; Hechtman, L.; Arnold, L.E.; Swanson, J.; Molina, B.S.G.; Sibley, M.H.; Howard, A.L. Childhood predictors of adult functional outcomes in the Multimodal Treatment Study of Attention-deficit/Hyperactivity disorder. J. Am. Acad. Child Adolesc. Psychiatry 2017, 56, 687-695. [CrossRef] [PubMed]

23. Margari, F.; Craig, F.; Petruzzelli, M.G.; Lamanna, A.; Matera, E.; Margari, L. Parents psychopathology of children with attention deficit hyperactivity disorder. Res. Dev. Disabil. 2013, 34, 1036-1043. [CrossRef] [PubMed]

24. Biederman, J.; Petty, C.R.; Clarke, A.; Lomedico, A.; Faraone, S.V. Predictors of persistence of ADHD: An 11-year follow-up study. J. Psychiatry Res. 2011, 125, 147-156.

25. Agha, S.S.; Zammit, S.; Thapar, A.; Langley, K. Maternal psychopathology and offspring clinical outome: A four-year follow-up of boys with ADHD. Eur. Child Adolesc. Psychiatry 2017, 26, 253-262. [CrossRef]

26. Ahmad, S.I.; Hinshaw, S.P. Attention-Deficit-Hyperactivity disorder, trait impulsivity and externalizing behavior in a longitudinal sample. J. Abnorm. Child Psychol. 2017, 45, 1077-1089. [CrossRef]

27. Hawes, D.J.; Dadds, M.R.; Frost, A.D.J.; Russell, A. Parenting practices and prospective levels of hyperactivity/ inattention across early- and middle-childhood. J. Psychopathol. Behav. Assess. 2013, 35, 273-282. [CrossRef]

28. Musser, E.D.; Karalunas, S.L.; Dieckmann, N.; Peri, T.S.; Nigg, J.T. Attention-deficit/Hyperactivity disorder develpmental trajectories related to parental expressed emotion. J. Abnorm. Psychol. 2016, 125, 182-195. [CrossRef]

29. Theule, J.; Wiener, J.; Tannock, R.; Jenkins, J.M. Parenting stress in families of children with ADHD: A meta-analysis. J. Emot. Behav. Disord. 2013, 21, 3-17. [CrossRef]

30. Gordon, C.T.; Hinshaw, S.P. Parenting stress as a mediator between childhood ADHD and early adult female outcomes. J. Clin. Child Adolesc. Psychol. 2017, 46, 588-599. [CrossRef]

31. Evans, S.; Sciberras, E.; Mulraney, M. The relationship between maternal stress and boys' ADHD symptoms and quality of life: An australian prospective cohort study. J. Pediat. Nurs. 2020, 50, e33-e38. [CrossRef] [PubMed]

32. Demmer, D.H.; Puccio, F.; Stokes, M.A.; McGillivray, J.A.; Hooley, M. The influence of child gender on the prospective relationship between parenting and child ADHD. J. Abnorm. Child Psychol. 2018, 46, 113-125. [CrossRef] [PubMed]

33. Breaux, R.P.; Harvey, E.A. A longitudinal study of the relation between family functioning and preschool ADHD symptoms. J. Clin. Child Adolesc. Psychol. 2019, 48, 749-764. [CrossRef] [PubMed]

34. Riddle, M.A.; Yershova, K.; Lazaretto, D.; Paykina, N.; Yenokyan, G.; Greenhill, L.; Abikoff, H.; Vitiello, B.; Wigal, T.; McCracken, J.; et al. The preschool Attention-Deficit/Hyperactivity Disorder treatment study (PATS) 6 year follow-up. J. Am. Acad. Child Adolesc. Psychiatry 2013, 52, 264-278. [CrossRef]

35. Lecendreux, M.; Silverstein, M.; Konofal, E.; Cortese, S.; Faraone, S.V. A 9-year follow-up of attention-deficit/hyperactivity disorder in a population sample. J. Clin. Psychiatry 2019, 7, 80. [CrossRef]

36. Agnew-Blais, J.C.; Polanczyk, G.V.; Danese, A.; Wertz, J.; Moffitt, T.E.; Arseneault, L. Evaluation of the Persistence, Remission, and Emergence of Attention-Deficit/Hyperactivity Disorder in Young Adulthood. JAMA Psychiatry 2016, 73, 713-720. [CrossRef]

37. Mattos, P.; Louzã, M.R.; Palmini, A.L.; de Oliveira, I.R.; Rocha, F.L. A multicenter, open-label trial to evaluate the quality of life in adults with ADHD treated with long-acting methylphenidate (OROS MPH): Concerta quality of life (CONQoL) study. J. Atten. Disord. 2013, 17, 444-448. [CrossRef]

38. Fenesy, M.C.; Teh, S.E.; Lee, S.S. Negative parenting moderates the prospective association of ADHD symptoms and youth social problems. J. Abnorm. Child Psychol. 2019, 47, 1583-1597. [CrossRef]

39. van Lieshout, M.; Luman, M.; Buitelaar, J.; Rommelse, N.; Oosterlaan, J. Does neurocognitive functioning predict future or persistence of ADHD? A systematic review. Clin. Psychol. Rev. 2013, 33, 539-560. [CrossRef] [PubMed]

40. van Lieshout, M.; Luman, M.; Twisk, J.W.; Faraone, S.V.; Heslenfeld, D.J.; Hartman, C.A.; Hoekstra, P.; Franke, B.; Buitelaar, J.; Rommelse, N.; et al. Neurocognitive predictors of ADHD outcome: A 6-year follow-up study. J. Abnorm. Child Psychol. 2017, 45, 261-272. [CrossRef]

41. Miranda, A.; Colomer, C.M.; Fernández, M.I.; Presentación, M.J.; Roselloó, B. Analysis of personal and family factors in the persistence of attention deficit hyperactivity disorder: Results of a prospective follow $\neg$ up study in childhood. PLoS ONE 2015, 10, e0128325. [CrossRef] [PubMed]

42. Muüller, U.; Asherson, P.H.; Banaschewski, T.; Buitelaar, J.K.; Ebstein, R.P.; Eisenberg, J.; Gill, M.; Manor, I.; Miranda, A.; Oades, R.D.; et al. The impact of study design and diagnostic approach in a large multi-centre ADHD. study. Part 1: ADHD symptom patterns. BMC Psychiatry 2011, 11, 55.

43. Wechsler, D. Escala de Inteligencia Para Niños de Wechsler Revisada (WISC-R) [Wechsler Intelligence Scale for Children-Revised]; TEA Ediciones: Madrid, Spain, 1993.

44. Conners, C.K. Conners' Parent Rating Scale-Revised: Long Version (CPRS-R:L); MHS: Ajax, ON, Canada, 2001. 
45. Wechsler, D. Wechsler Adult Intelligence Scale-Revised. (WAIS-R), 3rd ed.; The Psychological Corporation: San Antonio, TX, USA, 1981.

46. Conners, C.K.; Erhardt, D.; Sparrow, E. Conners' Adult ADHD Rating Scales (CAARS) Technical Manual. North Tonawanda; Multi-Health Systems: New York, NY, USA, 1999.

47. Arnold, D.; O'Leary, S.; Wolf, L.; Acker, M. The parenting scale: A measure of dysfunctional parenting in discipline situations. Psychol. Assess. 1993, 15, 137-144. [CrossRef]

48. Abidin, R. Parenting Stress Index, 3rd ed.; Pediatric Psychology Press: Charlosteville, VA, USA, 1995.

49. Antonovsky, A. Unraveling the Mystery of Health: How People Manage Stress and Stay Well; Jossey-Bass: San Franscisco, CA, USA, 1987

50. Antonovsky, A. The structure and properties of the sense of coherence scale. Soc. Sci. Med. 1993, 36, 725-733. [CrossRef]

51. Dubois, B.; Levy, R.; Verin, M.; Teixeira, C.; Agid, Y.; Pillon, B. Experimental approach to prefrontal functions in humans. Ann. N. Y. Acad. Sci. 1995, 769, 41-60. [CrossRef] [PubMed]

52. Avila, C.; Cuenca, I.; Felix, V.; Parcet, M.A.; Miranda, A. Measuring impulsivity in school-aged boysand examining its relationship with ADHD and ODD ratings. J. Abnorm. Child Psychol. 2004, 32, 295-304. [CrossRef]

53. Endicott, J.; Nee, J.; Harrison, W.; Blumenthal, R. Quality of life enjoyment and satisfaction questionnaire: A new measure. Psychopharm. Bull. 1993, 29, 321-326.

54. Mick, E.; Faraone, S.V.; Spencer, T.; Zhang, H.F.; Biederman, J. Assessing the validity of the quality of life enjoyment and satisfaction questionnaire short form in adults with ADHD. J. Atten. Disord. 2008, 11, 504-509. [CrossRef]

55. Weiss, M.D. Weiss Functional Impairment RATING Scale (WFIRS) SELF-Report; University of British Columbia: Vancouver, BC, Canada, 2000.

56. Canu, W.H.; Hartung, C.M.; Stevens, A.E.; Lefler, E.K. Psychometric properties of the Weiss functional impairment rating scale: Evidence for utility in research, assessment, and treatment of ADHD in emerging adults. J. Atten. Disord. 2020, 24, 1648-1660. [CrossRef]

57. Micoulaud-Franchi, A.; Weibel, S.; Weiss, M.; Gauchet, M.; Guichard, K.; Bioulac, S.; Phillip, P.; Jaussent, I.; Dauvillers, Y.; López, R. Validation of the French version of the Weiss functional impairment rating scale-self-report in a large cohort of adult patients with ADHD. J. Atten. Disord. 2018. [CrossRef]

58. Roth, R.M.; Isquith, P.K.; Gioia, G.A. BRIEF-A: Behavior Rating Inventory of Executive Function-Adult Version; Psychological Assessment Resources: Lutz, FL, USA, 2005.

59. WMA, World Medical Association, Declaration of Helsinki. JAMA 2013, 27, 2191-2194. [CrossRef]

60. Comas, M.; Valentino, K.; Borkowski, J.G. Maternal depressive symptoms and child temperament: Longitudinal associations with executive functioning. J. Ap. Dev. Psychol. 2014, 35, 156-167. [CrossRef]

61. Hughes, C.; Roman, G.; Hart, M.J.; Ensor, R. Does maternal depression predict young children's executive function?-A 4-year longitudinal study. J. Child Psychol. Psychiatry 2013, 54, 169-177. [CrossRef] [PubMed]

62. Biederman, J.; Faraone, S.; Milberger, S.; Curtis, S.; Chen, L.; Marrs, A.; Ouellette, C.; Moore, F.; Spencer, T. Predictors of persistence and remission of ADHD into adolescence: Results from a four-year prospective follow-up study. J. Am. Acad. Child Adolesc. Psychiatry 1996, 35, 343-351. [CrossRef]

63. Szentiványi, D.; Balázs, J. Quality of life in children and adolescents with symptoms or diagnosis of conduct disorder or oppositional defiant disorder. Ment. Health Prevent. 2018, 10, 1-8. [CrossRef]

64. Rosello, B.; Berenguer, C.; Raga, J.M.; Baixauli, I.; Miranda, A. Executive functions, effortful control, and emotional lability in adults with ADHD. Implications for functional outcomes. Psychiatry Res. 2020, 293, 113375. [CrossRef]

65. Hirsch, O.; Chavanon, M.L.; Christiansen, H. Emotional dysregulation subgroups in patients with adult attentiondeficit/hyperactivity disorder (ADHD): A cluster analytic approach. Sci. Rep. 2019, 9, 5639. [CrossRef]

66. Gordon, C.T.; Fabiano, G.A. The transition of youth with ADHD into the workforce: Review and future directions. Clin. Child. Fam. Psychol. Rev. 2019, 22, 316-347. [CrossRef]

67. Wolraich, M.L.; Chan, E.; Froehlich, T.; Lynch, R.L.; Bax, A.; Redwine, S.T.; Ihyembe, D.; Hagan, J.F. ADHD diagnosis and treatment guidelines: A historical perspective. Pediatrics 2019, 144, e20191682. [CrossRef]

68. Craig, F.; Savino, R.; Fanizza, I.; Lucarelli, E.; Russo, L.; Trabacca, A. A systematic review of coping strategies in parents of children with attention deficit hyperactivity disorder. Res. Dev. Dis. 2020, 98, 103571. [CrossRef]

69. Mani, A.; Khabir, L.; Mousavinasab, S.; Ghanizadeh, A. Effectiveness of group reduction on mental health, Mother's quality of life and behavioral problems in children with attention deficit hyperactivity disorder. Int. J. School Health. 2020, 7, 6-14.

70. Tercelli, M.S.; Ferreira, N. A systematic review of mindfulness based interventions for children and young people with ADHD and their parents. Glob. Psychiatry 2019, 2, 79-96. [CrossRef] 